\title{
Repensar a comunicação comunitária a partir da filosofia africana
}

\section{Rethinking community communication based on African philosophy}

Ana Lúcia Nunes de Sousal

Resumo: Este trabalho se propõe a estabelecer um diálogo teórico Sul-Sul entre as concepções contemporâneas da noção de comum e de comunicação comunitária. Parte de uma revisão bibliográfica narrativa sobre o tema, enfocando nas contribuições de Muniz Sodré e Raquel Paiva, mas também abordando outros autores ocidentais e latino-americanos. Logo, apresenta e reflexiona sobre a filosofia africana do comum, o Ubu-ntu, explicitando suas principais características. Por fim, argumenta a potência do Ubu-ntu para repensar e aprofundar os estudos de comunicação comunitária, a partir do sul global.

Palavras-Chave: Comunicação; comum; filosofia; sul global; Ubu-ntu.

Abstract: This work aims to establish a theoretical south-south dialogue between contemporary conceptions of common and community communication. It starts with a narrative literature review on the theme, focusing on the contributions of Muniz Sodré and Raquel Paiva, but also addressing other western and Latin-American authors. Then, it presents and reflects on the African philosophy of the common, the Ubu-ntu, explaining its main characteristics. Finally, it argues the power of Ubu-ntu to re-think and deepen the studies of community communication, from the global South.

Keywords: Communication; common; philosophy; south global; Ubu-ntu.

1 Universidade Federal do Rio de Janeiro (UFRJ). Rio de Janeiro, RJ, Brasil.

http://orcid.org/0000-0003-1924-5297 E-mail: anabetune@gmail.com 


\section{Introdução}

Na América Latina pulsam não só projetos de comunicação comunitária, como também teorias sobre este tipo de comunicação. Se, por um lado, temos a pujança da rádio rebelde (CUBA, 1959) e das rádios mineiras bolivianas, por outro, também temos um pensamento teórico que emerge destas práticas. E, assim como são diversas estas práticas, as perspectivas analíticas acabam por acompanhar este movimento ao longo do continente.

Para Kaplún (2007), a comunicação acabou por ser povoada por nomenclaturas similares como: a alternativa, a popular, a educativa, a comunitária, e a cidadã. Festa (1986), chegou a apontar, em sua pesquisa, 32 diferentes denominações. Apesar da diversidade, nos arriscamos a sintetizar algumas abordagens latino-americanas - sem o ânimo de esgotá-las, mas com o fim de compreendê-las em suas linhas gerais para logo passar à proposta central deste texto - em três grandes linhas: a comunicação popular, a alternativa e a comunitária.

Os trabalhos de Mario Kaplún (1987) - pesquisador argentino, radicado no Uruguai - sobre comunicação popular influenciaram, e continuam influenciando, pesquisas e projetos de comunicação latino-americanos. No Brasil, o termo foi popularizado pelos estudos das pesquisadoras brasileiras Regina Festa (1986) e, principalmente, Cicilia Peruzzo (2009). Já a comunicação alternativa, por sua vez, foi a abordagem à qual se dedicaram Margarita Graziano - socióloga argentina, radicada na Venezuela - e Máximo Simpson Grinberg - jornalista argentino, que desenvolveu sua carreira na Universidad Nacional Autónoma de México -, cujas primeiras obras datam do início dos anos 1980. Por último, a comunicação comunitária, que nas últimas décadas tem sido objeto de pesquisa e prática da brasileira Raquel Paiva e dos argentinos Oscar Magarola e Nelson Cardoso.

Kaplún defende que, na comunicação popular, o modelo comunicativo deve romper com a ideia de emissor e receptor para construir um "emi-rec", ou seja, um processo comunicativo horizontal, onde todos podem ser tanto emissores quanto receptores. Peruzzo (2009) também 
coloca o povo como o protagonista da comunicação popular. Para ela, a comunicação popular "é um instrumento político das classes subalternas” (PERUZZO, 2009, p. 5) para expressar-se. Berger (1989) reuniu alguns traços comuns encontrados na pesquisa sobre a temática: 1) expressão de um contexto de luta; 2) conteúdo crítico-emancipador; 3 ) espaço de expressão democrática; 4) o povo como protagonista; 5) instrumento das classes subalternas. Neste sentido, para a comunicação popular, o fundamental aponta à participação popular e à apropriação dos meios de comunicação de forma horizontal.

Outro conceito bastante difundido no contexto latino-americano, a comunicação alternativa, tem sido alvo de debates em virtude de sua inconstância (BAEZA, 2011). Graziano (1980) enxergava na comunicação alternativa uma estratégia totalizadora, que deveria ser projeto de uma vanguarda política. Para Grinberg (1986), este enfoque desconsiderava a práxis espontânea, deixando de fora uma série de iniciativas importantes. Para ele, é o uso social que transforma ou não um meio em alternativo. Ou seja, "é alternativo todo meio que, em um contexto caracterizado pela existência de setores privilegiados (...) implica uma opção frente ao discurso dominante" (GRINBERG, 1987, p. 30). Esta margem escolhida como batalha à hegemonia também é apontada por Sel (2009) e Peruzzo (2009). Assim, a batalha discursiva aparece como o elemento central da comunicação alternativa.

A comunicação comunitária, por sua vez, mais do que definir-se pelo discurso, estaria centrada em sua proposta social (PAIVA, 2003), no comprometimento com as comunidades onde se localiza e na ampliação dos direitos e deveres cidadãos (PERUZZO, 2004). Tanto Paiva quanto Peruzzo apontam, também, a necessidade da pluralidade de vozes na construção das mensagens, na gestão compartilhada dos meios e na participação ativa e horizontal da comunidade, na contribuição à educação e à cultura etc. Cardoso (2007 e 2000) e Magarola (2005) sugerem que a comunicação comunitária, teoricamente, estaria vinculada ao marxismo, aos estudos de recepção, à Teologia da Libertação e às teorias freireanas. 
O interessante é saber que, pese a muitos destes projetos serem desenvolvidos em territórios ancestrais de povos indígenas e descendentes de africanos, teorias que dialoguem com estas cosmopercepções não costumam ser apontadas como fontes destas práticas. O objetivo deste artigo não é agregar mais um conceito à disputa, mas oferecer uma perspectiva até então pouco explorada. Dentre os vários conceitos que enumeramos, acreditamos que a comunicação comunitária possui vários elementos que possibilitam uma análise deste conceito a partir da afroperspectiva.

Assim, nos propomos a pensar a comunicação comunitária a partir desta cosmopercepções, ou seja, sugerir um olhar que considere os pontos de vista, sistemas e modos de pensar e viver de matrizes africanas (NOGUERA, 2011). Esta perspectiva, apesar do racismo estrutural, atravessa a cultura brasileira de forma muito profunda, transformando a filosofia africana - especificamente a teoria Ubuntu - numa importante fonte epistemológica para pensar as manifestações comunitárias em nossa sociedade. É importante mencionar, como sugere Clifford (2014), que a filosofia comunitarista do Ubuntu (GYEKYE, 2003; MENKITI, 1984; RAMOSE, 2003) não rivaliza com as ideias comunitaristas propostas por outras correntes. Assim, propomos um diálogo teórico contemporâneo, Sul-Sul, sobre o conceito, partindo das teorizações de Sodré (2014) e Paiva (2003) - também abordando outros autores - para depois aterrissar nos sentidos da filosofia do Ubuntu e repensar a comunicação comunitária.

\section{A luta pelo comum e a comunicação}

Para Sodré (2014, p. 9), os humanos são seres comunicantes "porque relacionam ou organizam mediações simbólicas (...) em função de um comum a ser compartido". A comunicação tem, assim, em seu sentido mais profundo, a ideia de "compartilhar", "participar de algo" ou "colocar em comum” (SODRÉ, 2014, p. 10). Paiva (2003, p. 10) também vincula o comum à comunicação, ao defender que a comunidade é uma metáfora para "a construção de uma nova forma para o laço social". 
Paiva (2003) é categórica ao afirmar que há vários caminhos para compreender a comunidade. Estendemos esta assertiva à noção do comum. Sodré (2014) aponta para a necessidade epistemológica de fazer uma distinção entre o comum e a comunidade, sendo o primeiro uma disposição ontológica e o segundo uma subjetivação, que se manifesta de diferentes formas para cada comunidade específica. Em A Ciência do Comum: notas para o método comunicacional, publicado em 2014, Sodré realiza uma análise epistemológica profunda sobre o comum. Neste texto, se opta por não aprofundar nesta distinção, mas priorizar os pontos de confluência, aliando-se à sugestão de Paiva (2003), que afirma que, ao reflexionar sobre o comum, é importante evitar cair na idealização, transformando-o em um paraíso perdido e inalcançável.

Quando se fala do comum - principalmente considerando a irrupção de protestos em várias partes do mundo que o reivindicaram, a partir de 2011 - se está assumindo uma postura política. Escolher a "possibilidade comunitária” (PAIVA, 2003, p. 55) é assumir que há uma possibilidade real de construir um mundo no qual os "comuns" possam ter poder de decisão no que se refere aos problemas que os afetam. Neste sentido, a consigna "somos o 99\%", defendida pelo movimento Occupy, apareceu fortemente vinculada à reinvindicação de um comum a ser compartilhado. Quando falamos de compartilhar estamos evocando a ideia de solidariedade, que é uma "estratégia dos que, por viver na escassez ou na margem, constroem um saber particular de convivência e de experiência local" (PAIVA, 2003, p. 19). Desta forma, é bastante compreensível que as ideias em torno ao comum e à necessidade de solidariedade apareçam com maior força nos momentos de explosão das crises cíclicas do capital, como vem ocorrendo desde 2008.

Hardt e Negri (2011) defendem que o comum seja instituído como um projeto político. Laval e Dardot (2015), apontam para a ideia de que o conceito, como definido por Hardt e Negri, estaria conformado por quatro dimensões: 1) o que a natureza dá em todo o momento; 2) o que é gerado universalmente pela vida social; 3) o que resulta historicamente de cada época do capital; e 4) o que caracteriza as lutas 
contemporâneas. Desta forma, o comum de Hardt e Negri (2011) é um conceito suficientemente amplo para cobrir "o ar, a água, os frutos da terra e toda a generosidade da natureza" (p. 10): "os saberes, linguagens, códigos, informação, afetos”; a produção biopolítica, que tem seu lugar em uma ampla rede de produtores cooperativos; e, por último, todo o processo de aprendizagem dentro dos processos de luta política, como a "imanência da tomada de decisões no interior da multidão" (p. 14).

Por mais que se realize um esforço para enumerar ou simplificar as formas do comum, não há que perder de vista que “o comum é sentido antes de ser pensado ou expressado, portanto, é algo que reside diretamente na existência" (SODRÉ, 2014, p. 204) e emerge de "um ponto de convergência” (SODRÉ, 2014, p. 238), dos vínculos estabelecidos no estar-juntos cotidianamente. A função da comunicação neste processo seria, no sentido defendido por Sodré (2014), a de organizar todas estas dimensões do comum e os vínculos invisíveis que o unem.

Estes vínculos, pontos de convergência, laços visíveis e invisíveis, engendram uma relação entre os seres humanos. A comunidade é "o próprio ser como relação” (PAIVA, 2007, p. 19). Esta concepção da comunidade como uma relação também é proposta por Nancy (2000, p. 17): “o ser mesmo que chega a definir-se como relação, como não absoluto e se é desejado - pelo menos é o que pretendo dizer - como comunidade". Para Nancy (2000, p. 26), “a comunidade é o que tem lugar sempre através do outro e para o outro”. A comunidade deixa claro que "não há ser singular sem outro ser singular" (NANCY, 2000, p. 39), o que converge com as ideias de Negri (2010, p. 412), para quem não há possibilidade de pensar o ser humano como um corpo solitário, pois este somente existe na sua relação com o outro. O encontro entre os seres, este colocar o "ser em comum”, é, portanto, uma decisão política. É, por exemplo, a decisão que os tunisinos tiveram que tomar ao desobedecer a ordem judicial e sair, como multidão, à rua para acompanhar o enterro de Mohammed Bouazizi, em 2011, durante o que ficou conhecido como "primavera árabe"; ou dos egípcios, também em 2011, respondendo ao chamado de Azma Mahfouz para que tomassem as ruas em 
defesa da democracia no país. Decidir fazer com que o encontro entre os corpos e as experiências seja possível, que se concretize em ação no "ser em comum", que a relação, que o vínculo, que a abertura para o outro exista, esta é a decisão que é tomada cada vez que um movimento popular se forma e toma as ruas.

Partindo da análise de como o "compartilhar o espaço com o outro se funda na essência do ser, sendo possível perceber-se na medida em que se é descoberto pelo olhar do outro" (PAIVA, 2003, p. 87) realizaremos uma pequena digressão como aporte ao texto. A fortaleza de compartilhar o espaço e o encontro de olhares na construção do comum, defendida por Paiva, fica evidente, por exemplo, no encontro entre manifestantes que, mesmo mascarados, podiam se reconhecer após meses nas ruas, durante o ciclo de protestos de 2013, no Rio de Janeiro, ou nos aplausos de professores a jovens vestidos de negro, praticantes da tática Black Block, durante a manifestação de 15 de outubro de 2013, também no Rio de Janeiro. Este exemplo também é ilustrativo para compreender como "não se pretende abstrair a convivência das diferenças no regime comunitário" (PAIVA, 2003, p. 100). As diferenças dentro deste espaço compartilhado são possíveis porque, como afirma Nancy (2010), não há ser comum, há um ser "em” comum. O que se compartilha não é, portanto, o ser, mas a "exposição do ser, a declinação de si, o tremor sem rosto da identidade exposta: nos compartimos” (NANCY, 2010, p. 423).

Para Esposito, o que une os indivíduos em uma comunidade é um nada em comum. Assim, propõe que "não é o próprio, mas o impróprio - ou, mais drasticamente, o outro - o que caracteriza o comum” (ESPOSITO, 2003, p. 31). O autor ainda explica que a comunidade não é uma fusão de indivíduos que resulta num indivíduo maior, não é um laço coletivo que une a indivíduos que estiveram separados e não é um modo de ser. A comunidade seria, segundo a interpretação de Esposito (2003), a interrupção do fechamento do sujeito.

Quando se fala de fechamentos e aberturas também se chega a Rancière, que tem uma das propostas mais interessantes para pensar a ideia de comunidade na contemporaneidade. Rancière (2010) propõe a 
comunidade como dissenso, uma comunidade que coloca em jogo um mundo comum dentro de outro mundo comum. Para ele, “a política moderna foi feita destas aberturas de mundos comuns que colocam uma comunidade dentro da outra" (RANCIÈRE, 2010, p. 426).

Esta comunidade política existe em um momento específico: "cada vez que os corpos afirmam uma capacidade e ocupam um lugar distinto daquele que lhes é normalmente atribuído" (RANCIÈRE, 2010, p. 427). Aqui também se pode retomar o exemplo do povo tunisino ou egípcio já mencionado anteriormente, uma vez que a comunidade política se estabelece justamente quando estas mulheres e homens decidem ocupar um lugar diferente do que lhes havia sido designado. É nesta ação de partilhar o que era privado que se estabelece o comum, e instaurando o dissenso, é o que faz com que "sejam quebradas as regras de inclusão e os modos de visibilidade que as ordenam” (RANCIÈRE, 2010, p. 425). É exatamente neste momento que, inesperadamente, aparece a política e por isto, para Rancière, a comunidade é estritamente política e a política é comunitária:

A política aparece quando aqueles que não tem tempo, se tomam o tempo necessário para erguer-se como habitantes de um espaço comum e para demonstrar que sua boca emite perfeitamente uma linguagem que fala de coisas comuns, e não somente um grito que denota sofrimento. Esta distribuição e redistribuição de lugares e de identidades, esta partilha dos espaços e dos tempos, do visível e do invisível, do ruído da linguagem, constituem isto que eu chamo de "a divisão do sensível". A política consiste em reconfigurar a divisão do sensível, em introduzir sujeitos e objetos novos, em fazer visível aquilo que não era, em escutar como seres dotados de palavra àqueles que não eram considerados mais que animais ruidosos (RANCIÈRE, 2005, p. 13-14).

A política é o que ocorre quando se estabelece o dissenso, criando esta nova comunidade, que é política, na qual se criam novas relações, novos significados, novos lugares para os corpos e novos modos de identificação (RANCIÈRE, 2010). A luta de classes é a luta entre duas formas de comunidade, a que quer fazer que apareça esta nova comunidade política e a que quer impedir o processo (a comunidade policial). 
A possibilidade de repensar o comum e a comunidade a partir da política e a política a partir do comum permite uma reflexão dotada de uma potência revolucionária - que se acredita necessária - para compreender os movimentos de protesto que se desenvolveram no mundo contemporâneo. A comunidade dos $99 \%$ luta para introduzir sujeitos e objetos novos, para que o povo seja compreendido como ser dotado de palavra e ação, colocando seus corpos nas ruas e nas praças; transformando as barricadas nos lugares de reposicionamento do comum.

Este reposicionamento do comum pôde ser visto muito de perto durante as lutas que se desenvolveram nos últimos anos na América Latina. Abordando especificamente o caso boliviano, Aguilar (2017) afirma que um horizonte político comunitário-popular foi aberto, cujo nó central foi "a reapropriação coletiva da riqueza material disponível, da possibilidade de decisão sobre ela, ou seja, de sua gestão e usufruto” (p. 36).

A luta encarnada pelo povo boliviano nas últimas duas décadas foi por inverter a ordem de poder, "buscando instituir o direito de decidir em comum sobre a riqueza material existente”, em relação à água, aos hidrocarbonetos, à terra e ao território. As lógicas do comum, defendidas em armas pelos bolivianos, estavam concentradas na conservação e cuidado dos recursos materiais coletivamente disponíveis. Eles reivindicavam ser tratados como seres dotados de palavra e que as decisões sobre os assuntos que a todos afetam fossem coletivas.

A partir desta experiência, Aguilar (2017) defende que "o comum é o que se possui ou se compartilha coletivamente por vários” (p. 74). Dentro desta comunidade, são as mulheres e homens que compartilham este comum os que estabelecem as normas para o uso e transmissão dos direitos para as seguintes gerações. Esta lógica de produção do comum pode ser vista como uma "contemporânea reatualizacão prática, fundada, isso sim, em antigos saberes coletivos interiorizados - e reproduzidos - por aqueles que se associam para os fins do presente" (AGUILAR, 2017, p. 73).

Esta lógica de produção do comum, observada por Aguilar em vários países da América Latina (Abya Ayla), instiga a propor um olhar 
do comum a partir das noções afrocentradas, que fortemente habitam o imaginário e as práticas sociais brasileiras. Na próxima sessão, apresentaremos algumas reflexões sobre a comunidade a partir da filosofia africana, mais especificamente partindo do conceito de Ubuntu.

\section{O comum e o Ubuntu}

Analisar o comum a partir da afroperspectiva significa propor um olhar que considere os pontos de vista, sistemas e modos de pensar e viver das matrizes africanas (NOGUERA, 2011). Esta perspectiva atravessa a cultura brasileira de forma profunda, o que justifica, portanto, recorrer à filosofia africana para pensar as expressões do comum em nossa sociedade. É importante mencionar, como sugere Clifford (2004), que a filosofia comunitarista do Ubuntu não rivaliza com as ideias comunitaristas propostas a partir de outros marcos de pensamento, sendo, inclusive objeto de análise na sessão anterior deste texto. É importante situar como as ideias gerais sobre o comum, abordadas a partir da afrocentricidade, dialogam com aquelas defendidas pela filosofia eurocêntrica. Entretanto, não é a coincidência que chama a atenção, mas o fato de que esta relação não houvesse sido objeto de análise e reflexão anteriormente. Ramose (2005, p. 4) argumenta que pensar uma filosofia africana "considerou-se impossível como experiência, uma vez que o povo africano foi considerado, por natureza, incapaz de produzir qualquer filosofia". Desta forma, pensar a partir da filosofia africana possui uma dimensão "libertadora" para o autor, que também assumimos neste texto.

A fonte teórica que convocamos para esta aproximação é a filosofia negra sul-africana, oriunda dos povos banto e foi desenvolvida, de forma teórica e escrita, a partir dos anos 1980, principalmente na África do Sul e no Zimbábue. Assim, quando nos referimos a este conceito, no texto, é preciso ter em mente este contexto de desenvolvimento. Entretanto, os filósofos africanos argumentam que o caráter "comunal ou comunitário” (GYEKYE, 2003, p. 349) do pensamento africano é claramente 
expresso e é a linha demarcadora destas culturas, de acordo com Gyekye (2003).

Ubuntu é a base, o fundamento, a fonte na qual esta filosofia africana nasce e pela qual se desenvolve, de acordo com Gyekye (2003) e Ramose (2005). Assim, pensar a partir de Ubuntu é pensar a partir da filosofia africana, baseando-se na máxima banto "umunto ngumuntu nga bantu (motho he motho ka batho)", que segundo Ramose (2003, p. 272) significa que "ser uma pessoa humana é afirmar a própria humanidade pelo reconhecimento da humanidade do outro, e partindo desta base, estabelecer relações humanas entre si”.

Ubuntu, explica Ramose (2003), é uma categoria ontológica e epistemológica do pensamento africano dos povos de língua banto ${ }^{2}$, que guarda unicidade e indivisibilidade. Ubu é a existência e está sempre orientado ao desenvolvimento da própria humanidade, manifestando-se em formas particulares e modos de ser. Ntu é o ponto no qual essa existência assume sua forma concreta e particular de ser, no processo de desenvolvimento humano contínuo. Assim, Ubu está sempre orientado a Ntu. Dizer que Ubu está sempre orientado a Ntu, na explicação de Noguera (2011), indica que um ser humano somente pode se realizar como tal ao humanizar a outros seres humanos. O processo de desumanização, que está na raiz do racismo, por exemplo, impede que o ser humano desenvolva sua própria humanidade, pois ao não reconhecer a humanidade do seu semelhante se converte em um ser incapaz de conhecer a si próprio.

Outro aspecto importante para compreender Ubuntu, ainda ligado à totalidade e à indivisibilidade do conceito é a inter-relação tridimensional do ser. Para se realizar como ser, como Ubuntu, é preciso estar em equilíbrio com três aspectos da dimensão da experiência da vida: 1) o primeiro, Umu-ntu, que possibilita a fala, consequentemente possibilita o conhecimento do ser; 2) a relação com os abaphansi, que são os que já se foram do mundo dos vivos; aqueles cuja existência material

2 As línguas bantas são faladas por mais de 200 milhões de pessoas, em 22 dos 54 países africanos, na região do Níger-Congo. Teve uma influência marcante na língua portuguesa - ou pretuguês, para Lélia González - falada no Brasil. 
foi descontinuada de forma concreta e corporal, porém continua viva, livre, em contato e guiando o mundo dos vivos. Uma tradução livre de abaphansi, segundo Ramose (2005), teria se espalhado pela África e suas diásporas como "ancestrais"; 3) a terceira dimensão seria a dos seres que ainda não nasceram, os seres do futuro, cuja tarefa de fazer emergir seria dos vivos. O ser, em Ubuntu, estaria, portanto, vinculado aos que existem de forma material no presente, aos que vieram antes de nós e aos que virão depois de nós, revelando uma compreensão holística da existência. A vida, o ser, em todas as suas experiências, está ligado a estas três dimensões para a filosofia africana.

Desta forma, para as comunidades de matriz africana, este conceito é de suma importância, sendo obrigatório o cuidado com os abaphansi e com os seres do futuro. Os ancestrais têm a tarefa de guiar e proteger a família e a comunidade dos vivos. Na visão de mundo a partir de Ubuntu, o líder da comunidade, juntamente com os mais velhos, precisa cultivar uma boa relação com os seus mortos-vivos, seus abaphansi ou ancestrais.

Para o pensamento baseado em Ubuntu, a pessoa humana é um ser necessariamente comunitário, inserido num complexo contexto de relações interdependentes (GYEKYE, 2002; MENKITI, 1984), iniciando pela compreensão tridimensional do ser, mas não ficando por aí. O ser nunca é visto como um indivíduo isolado, mas imerso em uma trama de relações comunitárias que o definem parcialmente. Este "parcialmente" é extremamente importante. Para Gyekye (2003), a comunidade tem um grande papel em Ubuntu, já que é através das relações no seu interior que o ser humano se encontra, se realiza, se completa. Toda esta filosofia está centrada no caráter humano, entendendo que a racionalidade e a moralidade seriam adquiridas pelo ser através da convivência comunitária (CLIFFORD, 2004). Assim, este "eu comunitário" não está algemado e preso dentro da estrutura comunitária. É significativo chamar a atenção para o fato de que a partir de um olhar "afroperspectivista”, a comunidade não define a personalidade da pessoa, ainda que seja ela a chave para que esta emerja e também sua fonte de alimento. 
A comunidade pode ser interpretada como "um grupo de pessoas vinculadas por laços interpessoais, biológicos ou não, que se consideram como membros de um grupo e que tem interesses, objetivos e valores em comum" (GYEKYE, 2003, p. 351). O vínculo do ser humano com a comunidade está presente quando e enquanto existam interesses e valores comuns a ser compartilhados. O vínculo, lembra Sodré (2014), é de "natureza simbólica, de energia ou de força" (p. 301).

Outro princípio de Ubuntu que pode ser vinculado às lógicas do comum é o compartilhar, expresso nos provérbios "Gikuyu, Kiunuhu gitruagwo" e "Feta kgomo o tshware motho". O primeiro adverte que a avareza não alimenta; já o segundo afirma que em caso de ter que escolher entre a preservação da vida humana e a posse de riqueza, é imperativo escolher a primeira opção. A generosidade é fundamental neste modo de ver a vida, e aqui, como sugere Noguera (2011), não se trata de caridade, mas da ideia de que a realização pessoal passa necessariamente pela realização de outros seres humanos. Assim, "significa trabalhar em conjunto e fazer do resultado destes esforços um campo amplo para a circulação e proveito de todas as pessoas" (NOGUERA, 2011, p. 149). Mais que isto, explica Noguera (2011), Ubuntu é uma proposta de re-existência em um modo coletivo, no qual se trocam experiências e as relações são baseadas no apoio mútuo e na aprendizagem constante com outros seres humanos.

Como filosofia e ética (RAMOSE, 2003), Ubuntu pode ser vista como um valor universal, em qualquer lugar ou época em que se assuma a humanidade dos seres humanos e, por extensão, sua igualdade nesta condição de humanos. Ao propor este olhar, pensamos que é imprescindível ultrapassar o racismo epistemológico e valorizar a filosofia africana além do exotismo, assumindo que seus postulados não são aplicáveis somente ao continente africano, diaspórico ou a pequenos grupos. Assim, Clifford (2004, p. 242) propõe três formas primárias ou três contribuições da filosofia Ubuntu para as teorias sobre o comum:

1. mantém o foco dos comunitaristas de forma contundente no ser humano; 
2. previne a diferenciação entre o comunitarismo e o coletivismo;

3. torna iniludível a dimensão moral do comunitarismo.

Ao afirmar que Ubuntu contribui destas três formas ao comunitarismo, Clifford (2004) chama a atenção, principalmente, sobre como, ao abordar o comum a partir deste marco teórico, é possível manter-se enfocado na ideia do humano. Isto permite que, uma vez ultrapassada a discussão sociológica, se possa pensar no sentido mais básico de onde compartilhamos o comum: a humanidade. Considerar que todas as pessoas são humanas permitirá ao mundo ver-se como uma grande comunidade que compartilha este caráter comum.

\section{Comunicação comunitária e Ubuntu}

Acreditamos que Ubuntu, como conceito oriundo da filosofia africana, principalmente as de origem banto, cujas assunções estão centradas na comunidade pode, potencialmente, contribuir com reflexões originais sobre a comunicação comunitária realizada em contextos como o Brasil, fortemente influenciados pelas culturas e modos de vida de matrizes africanas. Traçamos a seguir alguns paralelos entre a comunicação comunitária e Ubuntu.

Para Ubuntu, considera-se que cada pessoa é portadora de conhecimento, podendo, assim, contribuir de forma valiosa para a comunidade no seu conjunto (CLIFFORD, 2004). O reconhecimento do outro e de seu valor dentro da comunidade (RAMOSE, 2003) é a base para o estabelecimento das relações comunitárias. Esta assertiva corrobora a ideia básica da comunicação comunitária, que vê a horizontalidade do processo comunicativo (KAPLÚN, 2007) como uma necessidade imperiosa.

Ubuntu também defende que as pessoas são capazes de articular suas próprias necessidades e as possíveis soluções para suas problemáticas, o que está em perfeita consonância com as ideias de Paiva (2003) e Peruzzo (2004; 2009), quando mencionam o controle comunitário, a gestão 
compartilhada, e a participação ativa e horizontal como características imprescindíveis à comunicação comunitária.

Outra conexão que encontramos entre estas duas perspectivas é apontada por Clifford (2004), que defende que narrar desde uma ótica Ubuntu permite criticismo, resistência e contribui profundamente à ética comunicativa, o que também está em concordância com os postulados que defendem uma posição crítica frente aos discursos e posições dominantes como uma batalha necessária à comunicação comunitária e alternativa (GRINBERG, 1987; SEL, 2009).

Além destes paralelos mencionados, há uma dimensão de Ubuntu que ainda não encontramos nos estudos de comunicação comunitária, mas acreditamos que é um aspecto novo que pode ajudar a re-pensar a comunicação comunitária em contextos como o sul global: a relação tridimensional do ser (RAMOSE, 2005).

Esta relação argumenta que o ser está ligado a Umu-ntu, que possibilita a fala e o conhecimento de si. Este primeiro aspecto nos leva a refletir como a necessidade de construir nossas próprias vozes é o que nos leva à comunicação comunitária e como, muitas vezes, são os projetos de comunicação comunitária que fazem emergir a potência comunitária, "o conhecimento de si". O segundo e o terceiro aspecto desta relação tridimensional, nesta hipótese, nos leva a pensar sobre a necessidade de, na comunicação comunitária, re-vincular-nos, na contemporaneidade, com "os que vieram antes de nós e os que virão depois de nós". O que pretendemos é pensar como a comunicação comunitária poderia se beneficiar com a vinculação entre os praticantes de comunicação comunitária de ontem - por exemplo, os que deram início às rádios e TVs comunitárias nos anos 1980 - com os novos praticantes, que se desenvolvem, principalmente, nas redes e mídias sociais da Internet, pensando sempre em fazer da comunicação comunitária uma via democrática e horizontal para as comunidades de amanhã.

Além disso, esta ideia de continuidade da existência tão disseminada entre a comunidade afrodiaspórica, que tem sua origem nesta relação tridimensional do ser, poderia, certamente, colaborar na manutenção 
dos projetos de comunicação comunitária, pois pensar na prática comunicativa através desta continuidade do ser possibilita uma compreensão holística da existência, não só individual, mas coletiva.

Nesta seção, procurei apontar alguns elementos convergentes entre as abordagens latino-americanas e o conceito de Ubuntu, além de outra conexão possível para pensar a comunicação comunitária através da ideia da relação tridimensional do ser, presente também em Ubuntu. É uma aproximação que ainda merece maior aprofundamento, mas podemos perceber, a partir destes elementos, como a filosofia africana pode ser um aporte poderoso para re-pensar e aprofundar os estudos de comunicação comunitária, a partir de um diálogo Sul-Sul.

\section{Palavras finais}

O objetivo deste trabalho foi propor uma outra forma de reflexionar sobre o comum, uma forma que a nosso ver, perpassa todas as relações e práticas sociais dos espaços que foram construídos a partir do mito da modernidade, este baseado no tráfico transatlântico de pessoas oriundas do continente que foi chamado de África ${ }^{3}$. Além disso, a afroperspectiva, que se baseia na filosofia africana, é uma ferramenta para a compreensão do mundo ampla e profunda o suficiente para que possa ser aplicada para além dos contextos que foram afetados pelo tráfico transatlântico de forma direta. Defendemos, assim, a universalidade da filosofia africana. Esta defesa, como afirma Ramose (2005) é um grito de resistência e de liberdade, pois parte de uma premissa antirracista e afirma que os povos de origem africana são seres capazes de produzir filosofia e ciência.

A filosofia africana ainda é bastante desconhecida e marginalizada nos contextos acadêmicos e foi com muita surpresa que nos deparamos com seus pressupostos e percebemos o quão condizente era pensar a comunicação comunitária a partir de Ubuntu. A dificuldade em encontrar textos dos filósofos africanos e daqueles que seguem a afroperspectiva ainda é um desafio, de forma que é preciso reconhecer que este trabalho

3 Ramose (2005) levanta a discussão de que o nome África foi um nome imposto pelos “conquistadores" e que, portanto, deveria ser usado como protesto. 
é ainda uma primeira aproximação ao conceito e precisa ser aprofundado nos próximos anos. Entretanto, é importante situar que as ideias aqui apresentadas são, majoritariamente, oriundas de fontes primárias da filosofia negro-africana.

O que a teoria do comum em Ubuntu nos traz é uma forma de interpretar o comum centrado no humano, já que Ubuntu é a própria humanidade do ser, que só se realiza a partir do outro; e aqui não é um outro como a outredade a ser evitada e/ou temida, mas como o outro que possibilita que a humanidade seja um comum a ser compartilhado por todas as pessoas. A forma holística de interpretação da filosofia africana faz com que não se possa ver o indivíduo de forma isolada, mas conectado a uma trama bastante complexa, que passa pela ancestralidade e pelos seres que ainda não estão materialmente no espaço terreno; pela solidariedade, generosidade e pelo bem-viver de toda a comunidade. Aspectos que são a base da comunicação comunitária e, por isso, o encontro teórico entre estas perspectivas nos parece auspicioso.

Para finalizar, podemos propor pensar a comunicação comunitária a partir da filosofia africana, a partir de Ubuntu. Uma comunicação comunitária afroperspectivista poderia ser fortemente vinculada aos laços comunitários; mais centrada no humano e menos dependente dos aparatos tecnológicos; narrada, decidida e gerida pelos próprios sujeitos, com voz e agência, de forma horizontal, compartilhada e democrática; intergeracional, respeitando os mais velhos e cuidando dos espaços, da natureza e dos processos para os mais jovens e os que virão depois; e integradora entre todas as pessoas da comunidade.

\section{Referências}

AGUILAR, R. G. Horizontes comunitario-populares. Producción de lo común más allá de las políticas estado-céntricas. Madrid: Traficantes de Sueños, 2017.

BAEZA, Chiara Saéz. Tercer sector de la comunicación. Teoría y práxis de la Televisión Alternativa. Una mirada a los casos de España, Estados Unidos y Venezuela. 2011. Tese (Doutorado em Comunicação) - Universidad Autónoma de Barcelona, Barcelona, 2011. 
BERGER, Christa. A Comunicação Emergente: Popular e/ou Alternativa no Brasil. Porto Alegre: UFRGS, 1989.

CARDOSO, Nelson. Apunte para la Cátedra Taller de Comunicación Comunitaria. La comunicación desde una perspectiva de comunicación comunitaria. Buenos Aires: Universidad de Buenos Aires, 2007.

CARDOSO, Nelson. Apunte para la Cátedra Taller de Comunicación Comunitaria. La comunicación comunitária. Buenos Aires: Universidad de Buenos Aires, 2000.

CLIFFORD, G. Christians. Ubuntu and communitarianism in media ethic. Ecquid Novi: African Journalism Studies, v. 25, n. 2, p. 235-256, 2004.

COYER, K.; DOWMUNT, T.; FOUNTAIN, A. The Alternative Media Handbook. London: Routledge, 2007.

ESPOSITO, Roberto. Comunnitas. Origen y destino de la comunidad. Buenos Aires: Amarrortu ediciones, 2003.

FESTA, Regina. Comunicação Popular e Alternativa no Brasil. São Paulo: Paulinas, 1986.

GRINBERG, Máximo Simpson. Comunicación alternativa: tendencias de la investigación en América Latina. In: GRINBERG, M. Simpson. Comunicación alternativa y cambio social. México, DF: Premia Editora, 1986.

GRINBERG, Máximo Simpson. Comunicação alternativa: dimensões, limites, possibilidades. In: GRINBERG, M. Simpson. A comunicação alternativa na América Latina. Petrópolis: [s. n.], 1987.

GYEKYE, Kwame. Person and Community in African thought. In: COETZEE, P. H.; ROUX, A. P. J. (Ed.). The African Philosophy Reader. New York: Routledge, 2003. p. 348-366.

HARDT, Michael; NEGRI, Antonio. Commonwealth. El proyecto de una revolución del común. Madrid: Akal, 2011.

KAPLÚN, Gabriel. La comunicación comunitaria en América Latina. In: DÍAZ, Bernardo (Org.). Medios de Comunicación. El escenario iberoamericano. Madrid: Fundación Telefónica, 2007.

KAPLUN, Mario. El Comunicador Popular. Buenos Aires: Editorial Humanitas, 1987.

KIDD, D. The global movement to transform communications. In: COYER, K.; DOWMUNT, T.; FOUNTAIN, A. The Alternative Media Handbook. London: Routledge, 2007.

LAVAL, Christian; DARDOT, Pierre. Común. Ensayo sobre la revolución del siglo XXI. Barcelona: Gedisa, 2015.

MAGAROLA, Oscar. Aproximaciones al fenómeno de la Comunicación Comunitaria. Apunte de cátedra. Buenos Aires: Universidad de Buenos Aires, 2005.

MENKITI, I. A. Person and Community in African Traditional Thought. In: WRIGHT, R. A. African philosophy: An Introduction. Lanham: University Press of America, 1984, p. 171-181.

NANCY, Jean Luc. La comunidad inoperante. Traducción de Juan Manuel Garrido Wainer. Santiago de Chile: ARCIS, 2000. 
NOGUERA, Renato. Ubuntu como modo de existência. Elementos gerais para uma ética afroperspectivista. Revista da ABPN, v. 3, n. 6, p. 147-150, 2011.

PAIVA, Raquel (Org.). O retorno da comunidade. Os novos caminhos do social. Rio de Janeiro: Mauad X, 2007.

PAIVA, Raquel. O Espírito Comum. Comunidade, mídia e globalismo. Rio de Janeiro: Maud X, 2003.

RAMOSE, Mogobe B. The ethics of Ubuntu. In: COETZEE, P. H.; ROUX, A. P. J. (Ed.). The African Philosophy Reader. New York: Routledge, 2003. p. 348-366.

RAMOSE, Mogobe B. African philosophy through Ubuntu. Harare: Mond Books Publishers, 2005.

RANCIÈRE, Jacques. A comunidade como dissentimento. In: A política dos muitos. Povo, classe e multidão. Lisboa: Editora Tinta da China, 2010.

SEL, Susana. Comunicación alternativa y politicas publicas en el combate latino-americano. In: Sel, Susana. La comunicación mediatizada: hegemonías, alternatividades, soberanías. Buenos Aires: Consejo Latino-americano de Ciencias Sociales - CLACSO, 2009.

SODRÉ, Muniz. A Ciência do Comum: notas para o método comunicacional. Petrópolis, RJ: Vozes, 2014.

\section{Sobre a autora:}

Ana Lúcia Nunes de Sousa - Professora Adjunta do Instituto NUTES de Educação em Ciências e Saúde, atuando no Laboratório de Vídeo Educativo e no Programa de Pós-graduação em Educação em Ciências e Saúde.

Data de submissão: 24/08/2020

Data de aceite: 04/02/2021 